\title{
A detailed post-IR IRSL dating study of the Niuyangzigou loess site in northeastern China
}

Yi, Shuangwen; Buylaert, Jan-Pieter; Murray, Andrew Sean; Lu, Huayu; Thiel, Christine; Zeng, Lin

Published in:

Boreas

Link to article, DOI:

$10.1111 /$ bor. 12185

Publication date:

2016

Document Version

Peer reviewed version

Link back to DTU Orbit

Citation (APA):

Yi, S., Buylaert, J-P., Murray, A. S., Lu, H., Thiel, C., \& Zeng, L. (2016). A detailed post-IR IRSL dating study of the Niuyangzigou loess site in northeastern China. Boreas, 45(4), 644-657. https://doi.org/10.1111/bor.12185

\section{General rights}

Copyright and moral rights for the publications made accessible in the public portal are retained by the authors and/or other copyright owners and it is a condition of accessing publications that users recognise and abide by the legal requirements associated with these rights.

- Users may download and print one copy of any publication from the public portal for the purpose of private study or research.

- You may not further distribute the material or use it for any profit-making activity or commercial gain

- You may freely distribute the URL identifying the publication in the public portal 
1 A detailed post-IR IRSL dating study of the Niuyangzigou loess site

2

3

4

5

6

7 Yi, S.W., Buylaert, J.-P., Murray A.S., Lu, H.Y. Thiel, C. \& Zeng L.: A detailed post-IR

8 IRSL dating study of the Niuyangzigou loess site in northeastern China.

9

10

11 luminescence (post-IR IRSL; pIRIR290) measurements made on sand-sized quartz ranges between $\sim 15$ and $\sim 80 \%$ of the total dose, and good dose recovery (within $\pm 5 \%$

17 of unity) can be obtained up to $\sim 800 \mathrm{~Gy}$. Otherwise, the dose recovery ratio deviates from unity. The $D_{e}$ values also depend on the test dose size so we conclude that the effect of test dose size should be routinely considered in pIRIR dating. First IR stimulation plateau pIRIR290 results are compared with multiple elevated temperature

21 -pIRIR (MET-pIRIR) data. It appears that the low temperature MET-pIRIR data are 22 strongly affected by poor dose recovery, but this is not the case for the pIRIR 290 
23 results. Natural signal measurements at the highest (first IR) stimulation temperature

24 on a sample expected to be in field saturation, suggest $\sim 10 \%$ signal loss is present in

25 pIRIR signals. Long term laboratory bleaching experiments ( $>80$ days) show that a

26 constant (or very difficult to bleach) residual pIRIR 290 signal is reached after $\sim 300 \mathrm{~h}$,

27 corresponding to a dose of 6.2 $\pm 0.7 \mathrm{~Gy}$. Quartz OSL and feldspar pIRIR50,290 ages are

28 in good agreement at least back to $\sim 70 \mathrm{ka}$. Beyond this the quartz ages begin to

29 underestimate but the feldspar ages are in agreement with the expected Last

30 Interglacial age palaeosol.

31

32 Shuangwen Yi (ysw7563@nju.edu.cn), Huayu Lu and Lin Zeng, School of Geographic and

33 Oceanographic Sciences, Nanjing University, Nanjing 210093, China; Jan-Pieter Buylaert

34 (e-mail: jabu@risoe.dtu.dk), Nordic Laboratory for Luminescence Dating, Department of

35 Geoscience, Aarhus University, Risø DTU, DK-4000 Roskilde, Denmark, and Technical

36 University of Denmark, Center for Nuclear Technologies, Risø Campus, DK-4000 Roskilde,

37 Denmark; Andrew S. Murray, Nordic Laboratory for Luminescence Dating, Department of

38 Geoscience, Aarhus University, Risø DTU, DK-4000 Roskilde, Denmark; Christine Thiel,

39 Leibniz Institute for Applied Geophysics, S3: Geochronology and Isotope Hydrology,

40 Hannover, Germany.

41 Northeastern China is located in the East Asian monsoon region and lies near the

42 present-day limit of the summer monsoon (Fig 1); as a result it is sensitive to the

43 global climate systems of both the high and low latitudes. Since the 1980s this area 
44 has been characterised by a pronounced regional temperature increase and a decrease in precipitation compared to the rest of China (Sun et al. 2007; Gao et al. 2008). Because of these factors it is a very suitable place to study climate change and

47 environmental evolution during the late Quaternary. The considerable area of loess deposits in north China forms one of the largest and most important aeolian records on Earth. Loess/palaeosol sequences contain detailed archives of terrestrial palaeoenvironmental changes and are highly sensitive to climatic changes, specifically to shifts in the Asian summer and winter monsoon and/or Northern Hemisphere westerly circulation (Liu \& Ding, 1998). However, research into loess deposition and past climate change in northeastern China is limited due to the lack of 54 independent age control (i.e. radiometric dating). Luminescence dating has proved to be particularly successful for dating aeolian

57 sequences (e.g. Stevens et al. 2006; Buylaert et al. 2008; Lai 2010;Lai \& Fan 2014).

58 These studies are all based on equivalent dose estimation using the single aliquot 59 regenerative (SAR) dose protocol developed for fast-component dominated quartz 60 OSL (Wintle \& Murray 2006). However, its use is typically limited to samples with 61 equivalent doses up to $150-200 \mathrm{~Gy}$. This restricts the OSL dating of quartz to loess 62 deposits (typical dose rate of between 3 and $4 \mathrm{~Gy} \mathrm{ka-1}$ ) from within the last 50-70 ka 63 (Buylaert et al. 2007; Roberts 2008; Chapot et al. 2012; Timar-Gabor \& Wintle 2013). 64 The infrared stimulated luminescence (IRSL) signal from feldspar (Hütt et al.1988) 
65

66

67

68

69

70

71

72

73

74

75

76

77

78

79

80

81

82

83

84

85

has the potential to extend the datable age range because it saturates at much higher doses compared to quartz OSL (Huntley \& Lamothe 2001). However, it is now widely accepted that IRSL measured at ambient temperature suffers from anomalous fading (e.g. Spooner 1994; Huntley \& Lian 2006; Buylaert et al. 2011, 2012). Recent advances in the understanding of feldspar as a luminescence dosimeter (Thomsen et al. 2008, 2011; Murray et al. 2009; Jain \& Ankjærgaard 2011) have led to new single-aliquot regenerative dose (SAR) dating protocols (so called post-IR IRSL protocols; e.g. Buylaert et al. 2009), in which a high temperature IRSL signal is measured at an increased temperature after a first IR stimulation at some lower temperature, usually close to ambient temperature. These post-IR IRSL (pIRIR) signals appear to be much less prone to fading than the conventional IRSL signal. Various single-aliquot based pIRIR dating protocols for feldspar have been developed; these include a two-step (e.g. Thomsen et al. 2008; Buylaert et al. 2009; Thiel et al. 2011a) and a multiple elevated temperature (MET) (Li \& Li 2011; 2012a) pIRIR stimulation procedure. These procedures have been shown to give accurate ages both for young (<10 ka, Fu \& Li 2013; Reimann et al. 2011, 2012) and old (>100 ka, Buylaert et al. 2012; Li \& Li 2011, 2012a; Kars et al. 2012; Zander \& Hilgers 2013) samples. Even though pIRIR measurement protocols have become the preferred method to measure feldspar equivalent doses, there are still remaining issues concerning dose recovery results (Roberts 2012), the determination of a potentially unbleachable component (e.g. Buylaert et al. 2011, Stevens et al. 2011; Murray et al. 
2012; Kars et al. 2014a) and signal (in)stability (Li \& Li 2012b; Thomsen et al. 2011).

87

88

The present work focuses on the Niuyangzigou (NYZG) loess-palaeosol

sequence in northeastern China (Fig. 1). The luminescence characteristics of quartz

SAR OSL and K-feldspar pIRIR signals (pIRIR290) are documented in a SAR-based

91

methodology. The pIRIR signal measured at $290^{\circ} \mathrm{C}$ is then investigated in detail to (i)

test the dependence of dose recovery and $D_{e}$ on test dose size, (ii) determine the size

of an (un)bleachable residual component and (iii) check the stability of the signal

94 (including MET-pIRIR signals) using a sample expected to be of non-finite age. Finally,

quartz OSL and pIRIR290 ages are compared and a luminescence chronology for the

upper part of the NYZG section is presented.

97

98 Geological setting, stratigraphy and sampling

99

100 Northeastern China extends from $40^{\circ}$ to $59^{\circ} \mathrm{N}$ and 110 to $135^{\circ} \mathrm{E}$, it includes the

101 provinces of Heilongjiang, Jilin and Liaoning, and the Inner Mongolia Autonomous

102 Region east of $110^{\circ} \mathrm{E}$ (Fig. 1). The major topographical features in this area are the 103 extensive Northeast Plain surrounded by a series of mountains and hills. The

104 Daxingan Mountains lie along the western side while the Xiaoxingan Range with a 105 northwest-southeast orientation lies to the north. 
108 County, Chifeng city, in the northeastern part of the Inner Mongolia Autonomous

109 Region (Fig. 1). The whole section is a $36.6 \mathrm{~m}$ thick series of loess intercalated by

110 palaeosols; it is accessible through a natural exposure of the upper $26 \mathrm{~m}$ and a 10.6

$111 \mathrm{~m}$ deep exploratory well. The magnetic characteristics of the Matuyama-Brunhes

112 palaeomagnetic boundary (0.78 Ma; Cande \& Kent 1995) have been identified

113 towards the bottom of the sequence and some evidence for the Jaramillo sub-chron is

114 exposed in a basal complex of palaeosols (Zeng et al. 2011).

$116 \quad$ Fifteen luminescence samples were collected using light-tight steel cylinders

117 (diameter $5 \mathrm{~cm}$, length $20 \mathrm{~cm}$ ) from the upper $3.2 \mathrm{~m}$ of a freshly excavated profile.

118 Based on field observations, this section comprises the upper Holocene soil (So), the

119 Last Glacial loess $\left(\mathrm{L}_{1}\right)$ and the Last Interglacial palaeosol $\left(\mathrm{S}_{1}\right)$ (Fig.1). One additional 120 sample (sample code 1535) was collected near the B/M boundary (Zeng et al. 2011)

121 to provide a feldspar sample of non-finite luminescence age (expected burial 122 dose >2000 Gy).

123

124 Sample preparation and analytical facilities

126 Samples were opened under subdued red light conditions and material from the outer

127 ends of each tube was used for dose rate and water content measurement. The 
128 non-light exposed material from the middle part of the tube was treated with $\mathrm{HCl}(30 \%)$

129 and $\mathrm{H}_{2} \mathrm{O}_{2}(30 \%)$ to remove carbonates and organic matter, respectively. Grains in the

130 range 63 to $90 \mu \mathrm{m}$ were obtained by wet-sieving. Pure quartz grains (no significant

131 IRSL signals) were obtained after a 40 min $\mathrm{HF}(40 \%)$ etch and 40 min $10 \% \mathrm{HCl}$ rinse.

132 For K-rich feldspar extraction, a portion of the initial 63-90 $\mu \mathrm{m}$ sieved fraction was

133 cleaned with $10 \%$ HF for 20 min to remove coatings and the outer alpha irradiated

134 layer, and then rinsed in $10 \% \mathrm{HCl}$ acid for 20 min to remove any precipitated fluorides.

135 K-rich feldspars were floated off using an aqueous heavy liquid (sodium

136 heteropolytungstate 'LST Fastfloat'; density $\left.2.58 \mathrm{~g} \cdot \mathrm{cm}^{-3}\right)$.

137

138

Luminescence measurements employed Risø TL/OSL readers model DA-20

139 (Bøtter-Jensen et al. 2003) equipped with blue LEDs (470 nm, $\left.\sim 80 \mathrm{mWcm}^{-2}\right)$ infrared

140 (IR) LEDs (870 nm, $\left.\sim 135 \mathrm{mWcm}^{-2}\right)$; each reader was equipped with a calibrated ${ }^{90} \mathrm{Sr}$

$141 \quad{ }^{90} \mathrm{Y}$ beta source. Quartz OSL signals were collected through $7.5 \mathrm{~mm}$ of Schott U-340

142 (UV) glass filter and feldspar (post-IR) IRSL through a combination of Corning 7-59

143 and Schott BG-39 glass filters (blue-violet part of the spectrum). Quartz grains were

144 mounted as large $(8 \mathrm{~mm})$ aliquots on stainless steel discs and K-rich feldspars as

145 small (2 mm) aliquots on stainless steel cups; Silicone oil (Silkospray) was used as an

146 adhesive. For quartz OSL, the signal was derived from the first $0.16 \mathrm{~s}$ of stimulation

147 and an early background (0.16-0.32 s) to minimize the influence of slow and medium

148 components (Ballarini et al. 2007; Cunningham \& Wallinga 2010). Feldspar (post-IR) 
149 IRSL signals were derived from the integral of the first $2 \mathrm{~s}$ of (post-IR) IRSL

150 stimulation, less a background based on the last $50 \mathrm{~s}$; for measurements made using

151 an MET-pIRIR protocol these intervals are 1 and $25 \mathrm{~s}$, respectively.

152

153 Dosimetry

154

155 The environmental dose rate was calculated from the uranium, thorium and 156 potassium concentrations, measured by neutron activation analysis (NAA). The in 157 situ water content (mass of moisture/dry mass) was determined by weighing the

158 sample before and after drying, and was assigned an absolute uncertainty of $\pm 5 \%$

159 (e.g. for a water content of $10 \%$ we have used $(10 \pm 5) \%)$. Using the revised dose rate

160 conversion factors of Guérin et al. (2011) and water content attenuation factors

161 (Aitken 1985), the elemental concentrations were converted into effective dose rate.

162 Calculation of the cosmic dose rate is based on Prescott \& Hutton (1994). For

$163 \mathrm{~K}$-feldspar dose rates a $\mathrm{K}$ concentration of $12.5 \pm 0.5 \%$ and $\mathrm{Rb}$ concentration of

$164400 \pm 100$ ppm was assumed (Huntley \& Baril 1997) consistent with earlier work on

165 sand-sized K-feldspar from Chinese loess (Zhao \& Li 2005; Li et al. 2008). A small

166 internal dose rate contribution from $\mathrm{U}$ and Th of $0.03 \pm 0.015 \mathrm{~Gy} \mathrm{ka}^{-1}$ and $0.06 \pm 0.03 \mathrm{~Gy}$

$167 \mathrm{ka}^{-1}$ was included for quartz and K-feldspar respectively (Mejdahl 1987; Zhao \& Li 168 2005; Vandenberghe et al. 2008). Table 1 summarises the uranium, thorium and 
169 potassium concentrations and the resulting total dose rates to quartz and K-feldspar

170 grains

171

172 Quartz OSL characteristics and resulting ages

173

174 The quartz equivalent doses $\left(D_{e}\right)$ were measured using a standard SAR protocol

175 (Murray \& Wintle 2000, 2003; Table 2). Typical dose response curves and OSL decay

176 curves (inset) are shown for the upper (138101) and lower (138115) samples in Fig.

$1772 \mathrm{~A}$ and $\mathrm{B}$, respectively. The blue-light stimulated OSL signals decrease very quickly

178 during the first second of stimulation, indicating that the signal is dominated by the

179 fast component (Jain et al. 2003; Singarayer \& Bailey 2003). In order to select

180 appropriate preheat conditions, the $\mathrm{D}_{\mathrm{e}}$ dependence on preheat temperature was

181 checked using a preheat plateau test. A plateau was observed for temperatures from

$182180{ }^{\circ} \mathrm{C}$ to at least $260{ }^{\circ} \mathrm{C}$ (Fig. 2C). The suitability of our adopted SAR protocol was

183 further checked with a dose recovery test (Murray \& Wintle 2003). The ratios of the

184 given doses to the measured doses were within $10 \%$ of unity over the entire

185 temperature interval (Fig. 2D). Based on these preheat tests, a $260^{\circ} \mathrm{C}$ preheat for 10

$186 \mathrm{~s}$ and $220{ }^{\circ} \mathrm{C}$ cut-heat was chosen for final $\mathrm{De}$ determination. For all samples,

187 recuperation is low (average $=0.06 \pm 0.01 \%$ of natural, $\mathrm{n}=245$ ) and the average

188 recycling ratio is $1.01 \pm 0.01(n=233)$ indicating that the adopted SAR protocol

189 successfully corrects for laboratory sensitivity changes. 
191 In order to ensure that only those aliquots that are capable of measuring the 192 dose of interest have been included in the calculation of the mean $D_{e}$, aliquots with $1932 \times D_{0}$ values that are smaller than the average dose (derived from all aliquots) are not 194 used in the derivation of $\mathrm{D}_{\mathrm{e}}$, irrespective of the $\mathrm{De}_{\mathrm{e}}$ value of the individual aliquot 195 (based on Thomsen et al. 2016; note that for simplicity our data were approximated 196 by a single saturating exponential function). For the upper four samples (<150 Gy) no 197 aliquots were rejected based on this criterion. Below this level $(1.20 \mathrm{~m})$ the 198 percentage of aliquots that are rejected ranges between 6 and 31\%. Over all the 15 199 samples the average $D_{e}$ was decreased by $\sim 3 \%$ because of this selection criterion; 200 the biggest decrease was $16 \%$ and the largest increase was only $2 \%$. Table 1 201 summarises the resulting $D_{e}$ values and quartz OSL ages. The calculated $D_{e}$ values 202 range from $92 \pm 3$ Gy for the upper sample to $270 \pm 13$ Gy for the lowest sample; the 203 corresponding ages are $30 \pm 2$ and $99 \pm 7 \mathrm{ka}$. We note that the bottom four samples all 204 have De values $\geq 200 \mathrm{~Gy}$. Several papers suggest that the upper limit of SAR based 205 quartz OSL dating lies around $\sim 200$ Gy in loess and ages derived from these high 206 doses should be interpreted with caution because they are likely to be 207 underestimates (e.g. Buylaert et al. 2007, 2008; Zhou \& Shackleton 2001; Lai 2010; 208 Chapot et al. 2012, Timar-Gabor \& Wintle 2013; Lai \& Fan 2014). 209

\section{Feldspar luminescence characteristics}


211 Dose response curve and $L_{x} / T_{x}$ plots

212 The SAR pIRIR 290 protocol proposed by Thiel et al. (2011a) and tested by Buylaert et 213 al. (2012) was used to measure the K-feldspar dose in these samples (Table 2). 214 Aliquots were preheated at $320{ }^{\circ} \mathrm{C}$ for $60 \mathrm{~s}$ followed by IR diode stimulation (90\% 215 power) at $50{ }^{\circ} \mathrm{C}$ for $200 \mathrm{~s}$ (the choice of this temperature is discussed in the next 216 section) to recombine nearby electron-hole pairs (Jain \& Ankjærgaard 2011). 217 Subsequently, a more stable IRSL signal is measured at $290{ }^{\circ} \mathrm{C}$ for $200 \mathrm{~s}$ (referred to 218 as pIRIR 290$)$; this is the dating signal of interest. The response to the test dose is 219 measured in the same manner and is followed by an IR illumination at $325{ }^{\circ} \mathrm{C}$ for 200 $220 \mathrm{~S}$ at the end of each SAR cycle, to reduce recuperation. Representative K-feldspar 221 pIRIR 290 and quartz OSL dose response curves (normalised to the fitted saturation 222 values) are presented for the lowermost sample (138115) in Fig. 3A. It can be seen 223 that the feldspar pIRIR 290 dose response curve has a much more extended dose 224 range compared to quartz OSL, 86\% of saturation is reached at 1250 and 310 Gy, 225 respectively. This extended feldspar range indicates its usefulness for dating samples 226 beyond the quartz OSL limit.

227

One of the main assumptions when using the SAR protocol to measure a dose is 229 that the test dose luminescence sensitivity is directly proportional to the preceding 230 regenerative dose; i.e. it can correct for sensitivity changes (Murray \& Wintle 2000). 231 We have constructed $L_{x}-T_{x}$ plots for the pIRIR290 signal for five samples down our 
232 section by repeating SAR cycles using a fixed regenerative dose and test dose (Fig.

$233 \mathrm{3B}$ ); there is clear proportionality between regenerative and test dose signals

234 indicating that the test dose successfully corrects for sensitivity changes. This is also

235 supported by the mean recycling ratio of $1.031 \pm 0.002(n=109, R S D=2 \% ; 15$

236 samples). If no test dose is used for sensitivity correction, the resulting recycling ratio

237 is $1.099 \pm 0.011$ with a much higher standard deviation of $10 \%$. For all samples,

238 recuperation is small ( $<3 \%$ of the natural signal) showing that our high temperature

239 clean-out is sufficiently stringent. However, the most stringent test for any SAR

240 protocol is the dose recovery test (Murray 1996; Wallinga et al. 2000; Murray \& Wintle

$2412003)$ and this is addressed in the next section.

242

\section{Dose recovery test}

244 Although several studies have presented good/acceptable dose recovery results for

245 pIRIR 290 protocols on a variety of sediments (e.g. Buylaert et al. 2011, 2012, 2013;

246 Nian et al. 2012; Thiel et al. 2012; Tsukamoto et al. 2014), there is also considerable

247 evidence for poor dose recovery results (e.g. Stevens et al. 2011; Lowick et al. 2012;

248 Roberts 2012; Thiel et al. 2011b, 2014 ; Murray et al. 2014). Usually, these poor dose

249 recovery ratios were significantly greater than unity. Some authors report difficulties in

250 bleaching natural pIRIR 290 signals (using SOL2 simulator or natural daylight); these

251 can result in poor dose recovery because of incorrect residual dose estimation (e.g.

252 Stevens et al. 2011; Alexanderson \& Murray 2012). To avoid potential complications 
253 related to bleaching natural samples, a dose recovery test can also be performed on

254 modern/young samples by adding a beta dose on top of a relatively small natural

255 dose (e.g. Buylaert et al. 2011); this is the approach taken in this study.

256

257 We investigated the dependence of dose recovery ratios on test dose size by 258 adding beta doses (ranging from 99 to $1593 \mathrm{~Gy}$ ) to aliquots of the uppermost sample 259 (138101) which has a pIRIR $290 D_{e}$ value of $\sim 100 \mathrm{~Gy}$. The dose recovery ratio was 260 calculated as the measured dose divided by the sum of the natural and the given 261 dose. Qin \& Zhou (2012) suggested that the dose recovery ratio is dependent on the 262 test dose size (their Fig. 3B) but their data are limited in test dose range and 263 inconclusive (the data for different test dose sizes does not differ significantly). Fig 4A 264 shows the dose recovery ratio as a function of test dose size over a wide test dose 265 range $(5-260 \%$ of the total (natural+added) dose). For small test doses $(<15 \%)$, the 266 dose recovery ratio is significantly greater than unity. In contrast, large test doses 267 (>80\%) yield ratios lower than unity. The best dose recovery ratios (within $\pm 5 \%$ of 268 unity) are found when the test dose ranges between $\sim 15$ and $\sim 80 \%$ of the total dose.

269 The data of Fig. 4A are also shown in Fig. 4B but now as a measured versus added 270 dose plot; these are so-called Single Aliquot Regenerative Added dose (SARA; 271 Mejdahl \& Bøtter-Jensen 1994; Wallinga et al. 2001) dose response curves. As 272 expected from the dose recovery ratios, the slope $(1.01 \pm 0.02)$ of the fitted line is 273 indistinguishable from unity when test doses between 15 and $80 \%$ are used. It is 
274 interesting to note that at least for added doses larger than about $600 \mathrm{~Gy}$, the data 275 measured with small $(<15 \%)$ or large $(>80 \%)$ test doses do not follow a simple 276 straight line relationship between measured and added dose, rather the measured 277 dose increasingly deviates from the known added dose; this occurs because of a 278 systematic change in Do with test dose.

279

280

We conclude from the data of Fig. 4 that, at least for these samples, an 281 acceptable dose recovery ratio is best ensured by using a test dose in the range $15-80 \%$ of the total (natural + added) dose.

\section{Equivalent dose}

285 Effect of test dose size. Fig. 5 shows the dependence of $D_{e}$ on test dose size for the uppermost (138101), middle (138108) and lowermost (138115) samples from the section. Sample 138101 shows a clear $D_{e}$ plateau for test doses ranging between 5 288 and $80 \%$ of the $\mathrm{De}_{\mathrm{e}}$ value; the $\mathrm{D}_{\mathrm{e}}$ value of the older samples appears insensitive to test 289 dose size over a shorter range, up to only $\sim 60 \%$. The shape of the dose recovery 290 ratio versus test dose curve (Fig. $4 \mathrm{~A}$ ) broadly resembles the shape of the $\mathrm{D}_{\mathrm{e}}$ versus 291 test dose curve but it appears that especially for low test doses $(<20 \%)$ the $\mathrm{De}_{\mathrm{e}}$ value is 292 less sensitive to test dose size than the dose recovery value. Nevertheless, for these 293 samples, it appears to be inappropriate to use very small $(<10 \%)$ or very large $(>60 \%)$ 294 test doses because of poor dose recovery ratios. For the remainder of this study we 
295 adopt a test dose size of $\sim 30 \%$ for $D_{e}$ measurements; in this range the dose recovery 296 ratio is within $\pm 5 \%$ of unity and the $D_{e}$ values are consistent with the plateau regions 297 in De versus test dose graphs.

298

299 Comparison with MET-protocol. Based on the model prediction by Jain \& 300 Ankjærgaard (2011) that the stability of the post-IR IRSL signal could be dependent 301 on the first IR stimulation temperature and/or wavelength, Buylaert et al. (2012) have 302 suggested the use of a first IR stimulation temperature plateau to investigate whether a stable signal was reached (interval over which $D_{e}$ is insensitive to prior IR 304 stimulation temperature). Fig. $6 A, B$ shows $D$ e as a function of prior IR stimulation 305 temperature for the top (138101) and bottom (138115) samples of the section, 306 respectively; from these data it seems that for $D_{e}$ values up to $\sim 400 \mathrm{~Gy}$ the $D_{e}$ is 307 insensitive to first IR stimulation temperature and a stable signal is observed. This is 308 in agreement with the data of $\mathrm{Li} \& \mathrm{Li}(2012 \mathrm{~b})$ who compared pIRIR50,290 $\mathrm{De}_{\mathrm{e}}$ values with 309 pIRIR200,290 De values and MET-pIRIR250 results for Luochuan samples and showed 310 that the three methods are indistinguishable back to $\sim 400 \mathrm{~Gy}$; they also showed that 311 beyond this a low temperature IR cleaning at $50{ }^{\circ} \mathrm{C}$ is apparently not sufficient to 312 recombine all nearby electron-hole pairs. Beyond $\sim 400 \mathrm{~Gy}, \mathrm{pIRIR} 200,290$ is consistent 313 with the MET-250 data. It is claimed by Li \& Li (2011, 2012a, b) and Fu \& Li (2013) 314 that the MET-pIRIR protocols have an advantage over the two-step protocols 315 (Buylaert et al. 2009, 2012; Thiel et al. 2011a) because of the possibility to construct 
316 "age-temperature" plots from individual aliquots; the presence of an "age plateau" at

317 higher stimulation temperatures is used to determine whether a stable signal was

318 identified. We have also measured the MET-pIRIR signals (following Li \& Li, 2012 a)

319 for the top and bottom sample of our section and the data are also shown in Fig. 6A,B

320 (open symbols). As expected the MET-pIRIR De values are consistent with the

321 pIRIR $290 D_{e}$ measurements when stimulation temperatures of $>200{ }^{\circ} \mathrm{C}$ are reached. It

322 should be noted that the plateau identified by Li \& Li (2011, 2012a) and Fu \& Li (2013)

323 is usually limited to two (or maximum three) datapoints over a limited temperature

324 interval of $50-100{ }^{\circ} \mathrm{C}$ (e.g. Li \& Li, 2011, 2012a). The same observation is made here.

325 For sample 138101 we have carried out a dose recovery test as a function of prior IR

326 stimulation temperature (Fig. 6C). It can be seen that dose recovery is satisfactory

327 over a wide prior IR stimulation temperature interval between 50 and $260{ }^{\circ} \mathrm{C}$ for the

328 pIRIR 290 data. This is in contrast with the MET-pIRIR dose recovery data which shows

329 a pronounced increase in of dose recovery between 50 and $150{ }^{\circ} \mathrm{C} I \mathrm{R}$ stimulation

330 temperature; the shape is very similar to the MET-pIRIR De data shown in Fig. 6A for

331 the same sample. We conclude that the MET-pIRIR $D_{e}$ data are significantly affected

332 by dose recovery problems at low IR stimulation temperatures (a suggestion to this

333 effect was made in Li \& Li 2011). This is consistent with the observations of Kars et al.

334 (2014b) who showed that high preheats $\left(>300^{\circ} \mathrm{C}\right)$ should not be used with low 335 temperature IR stimulations. Because of this, we suggest using first IR stimulation 
temperature plateaus instead of the MET-method to determine whether a more stable

337 signal has been reached.

339 Stability. Thiel et al. (2011a) were the first to show a natural pIRIR 290 signal in

340 saturation on the laboratory dose response curve for a sample collected below the

$341 \mathrm{~B} / \mathrm{M}$ boundary; this led them to conclude that the pIRIR 290 signal is a stable signal.

342 Other studies have made the same observation for pIRIR290 (Buylaert et al. 2011;

343 Thomsen et al. 2011) and the high-temperature MET-pIRIR signals (Li \& Li 2011,

344 2012a). In order to investigate this for our material, we collected a sample (code 1535,

$34527.30 \mathrm{~m}$ ) below the B/M boundary defined using palaeomagnetic measurements

346 (Zeng et al. 2011). The expected burial dose is $>2000$ Gy and all natural signals are

347 expected to be in field saturation.

Natural signals and dose response curves were measured for both the pIRIR 290

350 signals (using different prior-IR stimulation temperatures) and the MET-pIRIR signals.

351 The natural signals are shown in Fig. 7, expressed as a fraction of the saturation level

352 of the laboratory dose response curves. Note that for simplicity a single saturating 353 exponential was fitted through the data; Guralnik et al. (2015) have shown that for 354 their sample a single exponential fit gives a $D_{0}$ indistinguishable from that obtained 355 from their theoretically based generalised growth curve. Because most earlier work 
356 tended to use relatively small test doses, in this experiment we use both a large (500

357 Gy, approximately equal to $\left.D_{0}\right)$ and a small (50-60 Gy) test dose.

358 The results obtained using a 500 Gy test dose are discussed first (Fig. 7A). For 359 the pIRIR290 protocol, lower first-IR stimulation temperatures $\left(50-140{ }^{\circ} \mathrm{C}\right)$ yield 360 fraction of saturation values of less than 0.90 (average $=0.87 \pm 0.01$ ) and higher 361 temperatures $\left(170-260{ }^{\circ} \mathrm{C}\right.$ ) yield higher values (average $=0.92 \pm 0.01$ ). The 362 MET-pIRIR data measured with a 500 Gy test dose does not seem to show a clear 363 plateau at higher temperature (previously reported at $250-300^{\circ} \mathrm{C}$; see Fig. 3 in $\mathrm{Li} \& \mathrm{Li}$ $3642012 a)$. At 250 and $300{ }^{\circ} \mathrm{C}$ the fraction of saturation is $0.93 \pm 0.01$ and $0.965 \pm 0.004$, 365 respectively. Both for pIRIR 290 (measured with prior IR stimulation $\geq 170{ }^{\circ} \mathrm{C}$ ) and the 366 MET-pIRIR protocols, the data are not consistent with unity ( $\sim \%$ below saturation 367 light level for MET and $\sim 8 \%$ for pIRIR 290 ) which might suggest instability in the 368 pIRIR 290 signal and the high-temperature MET-pIRIR signals. For the pIRIR 290 signals 369 measured with low prior-IR stimulation temperatures this underestimation increases 370 to $\sim 13 \%$.

372 Fig. 7B shows the results when a small test dose of 50-60 Gy is used. For both 373 pIRIR 290 (only measured at 50 and $200^{\circ} \mathrm{C}$ prior-IR stimulation temperature) and the 374 MET-pIRIR signals the fraction of saturation appears to have increased significantly. 375 For the pIRIR 200,290 this value is $0.99 \pm 0.02$, consistent with the MET-pIRIR signals 376 measured at 250 and $300{ }^{\circ} \mathrm{C}(0.96 \pm 0.02)$; this could be interpreted as suggesting 
377 negligible instability. However, given the test dose dependence of the dose recovery 378 and $D_{e}$ results, it is not surprising that the fraction of saturation reached by a natural 379 signal is also a function of test dose size. One must be critical of saturation 380 measurements made with a test dose of only $60 \mathrm{~Gy}(<<10 \%$ of the natural dose). The 381 measurements made with a 500 Gy test dose $\left(\sim D_{0}\right)$ are more likely to yield accurate 382 De measurements and so more accurate measurements of saturation level. We 383 conclude that the apparent stability of signals (e.g. Fig. 1 in Buylaert et al. 2012 384 pIRIR; Li \& Li 2012a - MET-pIRIR) measured with a small test dose is likely to be an 385 artefact of the dose recovery dependence on test dose size, and that the small but 386 finite apparent instability (up to $\sim 8 \%$ below saturation) observed at saturation using a 387 large test dose is probably real.

To further investigate the stability of pIRIR signals we have measured fading 390 rates ( $g_{2 \text { days }}$ values) on sample 138106 using a 50 and $200{ }^{\circ} \mathrm{C}$ prior-IR stimulation 391 temperature. The resulting $g_{2 \text { days }}$ values are $0.75 \pm 0.10 \% / d e c a d e ~(n=6)$ and $3920.37 \pm 0.13 \% /$ decade $(n=6)$ for pIRIR 50,290 and pIRIR 200,290 respectively. It appears 393 that the pIRIR 200,290 fading rate is lower than the pIRIR50,290 fading rate; this is 394 consistent with the saturation measurements on sample 1535 presented earlier. Li \& $395 \mathrm{Li}(2012 \mathrm{~b})$ have also argued that pIRIR 200,290 is more stable than pIRIR50,290. 

summarises the quartz $\mathrm{OSL}, \mathrm{IR} 50$ and pIRIR 290 ages for all 15 samples. All the $\mathrm{IR}_{50}$ data are consistent with a smooth curve passing through the origin and lying below 401 the 1:1 line; this is what would be expected from samples for which both signals are 402 well-bleached at deposition but for which the IR50 signal is significantly unstable 403 compared to pIRIR290 (Buylaert et al. 2013). This result is not surprising given the 404 prolonged and almost ideal light-exposure received by wind-blown dust before final 405 deposition. Note that this relationship does not arise because of a dose-dependent 406 change in initial sensitivity of the IRSL signals (see Fig. S1). Although the scatter in the quartz and pIRIR age relationship is larger, the data are consistent with the fitted curve and there is again no evidence for pIRIR 290 outliers at larger ages.

410 To illustrate the likely initial conditions of this material had it not been well-bleached, 411 we exposed quartz and feldspar aliquots of the oldest sample (138115) to a SOL2 412 spectrum at a lamp-sample distance of $\sim 80 \mathrm{~cm}$ for various lengths of time. It took $413 \sim 130 \mathrm{~s}$ for the pIRIR290 dose, $\sim 20 \mathrm{~s}$ for the $\mathrm{IR}_{50}$ dose and $<2 \mathrm{~s}$ for the quartz OSL 414 dose to be reduced by $50 \%$. The resulting residual dose are shown as open circles 415 (IR50) and open stars (quartz OSL) in Fig. 8B, plotted against the residual pIRIR 290 416 doses. The differential bleaching rates of the three signals are obvious and each 417 dataset has been fitted with a single and double exponential; when the residual 418 quartz OSL dose is less than $10 \%$ of its initial value the IR50 dose is $\sim 55 \%$ of its initial 
419 value and the pIRIR 290 is $>80 \%$, comparable to the results described by Murray et al. 420 (2012). As expected both curves point at the origin - sufficient light exposure will

421 bleach all three signals so that the apparent residual doses are close to zero. Had our 422 loess samples been incompletely bleached in nature at deposition then the observed 423 IR $_{50}$ and pIRIR 290 doses would have grown along a line parallel to the solid line but 424 starting from some point on the dashed line passing through the open circles, 425 depending on the degree of incomplete bleaching. Given the inevitable variation in 426 the degree of incomplete bleaching with time this would have resulted in scattered 427 points lying below the observed solid line (as was seen by Buylaert et al. 2013). Since 428 our data do not show such scatter we conclude that the pIRIR290 signals (and thus the $429 \mathrm{IR}_{50}$ and quartz OSL signals) from these samples were all well-bleached at 430 deposition.

432 Residual component. Thomsen et al. (2008) and Buylaert et al. (2009) have shown 433 that some pIRIR signals can be readily bleached (with residual doses <2 Gy); these 434 levels are insignificant when older sediments are dated. However, more recent work 435 has found a much wider ranges in residual doses (2 to >20Gy) after natural and 436 laboratory bleaching of the pIRIR 290 signal (Thiel et al. 2011a, b; Buylaert et al. 2011, 437 2012; Stevens et al. 2011; Lowick et al. 2012; Murray et al. 2012, 2014; Sohbati et al. 438 2012; Kars et al. 2014a). The curve fitted through the open circles in Fig. 8B suggests 439 that it is possible to bleach the pIRIR 290 signals to relatively small doses but it is not 
440 clear whether there may be an unbleachable component. To investigate the degree to

441 which our pIRIR290 signal is bleachable, we have repeated the experimental 442 procedures described by Sohbati et al. (2012). A set of 225 aliquots was prepared for 443 each of three samples from the top, middle and bottom of the of the loess sequence $444(138102,138108,138115)$. These were exposed in groups of three to twelve aliquots 445 per sample for various lengths of time (3.7 to $4171 \mathrm{~h}$ ) in a Hönle SOL2 simulator at a 446 lamp-sample distance of $80 \mathrm{~cm}$. The apparent dose was measured using the pIRIR 290 447 protocol. The results are summarized in Fig. 9A (pIRIR 290$)$ and Fig. 9C (IR50). There is 448 a clear tendency for the residual doses to increase with equivalent dose ( $\left.D_{e}\right)$. 449 Extrapolation of these residual doses to a De of zero Gy can be used to predict the 450 average residual dose that would have been present in these samples before burial 451 had they been exposed to these light levels (Buylaert et al. 2012; Sohbati et al. 2012; 452 Kars et al. 2014a). The inset to Fig. 9A shows this relationship for all 15 samples for a $45315 \mathrm{~h}$ Sol2 bleach. The intercepts of the three samples bleached for various lengths of 454 time are plotted against exposure time in Fig. 9B,D for pIRIR290 and IR50 signals, 455 respectively. In both cases this residual appears to be consistent with a constant (or 456 very difficult to bleach) dose after a bleaching time of $\sim 300 \mathrm{~h}$. In our view it is likely 457 that these apparently constant difficult-to-bleach signals were present in these 458 samples at the time of deposition and accordingly a pIRIR 290 residual dose of $6.2 \pm 0.7$ 459 Gy has been subtracted from all measured De values used to calculate the pIRIR 290 460 ages given in Table 1. 


\section{A chronology for the NYZG section: comparison of quartz and}

\section{feldspar ages}

464

465 Fig. 10A presents the quartz and pIRIR 290 feldspar ages on a simplified section of the 466 NYZG site. All of the quartz and feldspar ages are consistent with each other down to a depth of $2.60 \mathrm{~m}$ corresponding to an age of $\sim 70 \mathrm{ka}$. The quartz dose in the $71 \pm 5 \mathrm{ka}$ sample (138112 at $2.60 \mathrm{~m}$ ) is $212 \pm 10 \mathrm{~Gy}$, consistent with the $\sim 200$ Gy limit suggested by Buylaert et al. $(2007,2008)$. This agreement is clearer in Fig. 8A which shows that

470 there is no easily detectable systematic deviation between quartz and feldspar below

$471 \sim 80$ ka. Only the oldest three samples show significant deviation.

472

The data suggest that the clearly defined soil at the bottom of this section below

$4742.8 \mathrm{~m}$ is consistent with deposition during the MIS 5 (130-75 ka). The sedimentation

475 rate during this period increases dramatically from $0.0063_{-0.0017}^{+0.0034} \mathrm{~m} \mathrm{ka}^{-1}$ during the 476 interglacial to $0.16_{-0.05}^{+0.12} \mathrm{~m} \mathrm{ka}^{-1}$ during the subsequent glacial period. The $\mathrm{L}_{1}$ loess 477 from $\sim 2.7$ up to $1.2 \mathrm{~m}$ accumulated over a time period that is small compared to our 478 uncertainties. There may be a discontinuity above $1.2 \mathrm{~m}$ where the feldspar age

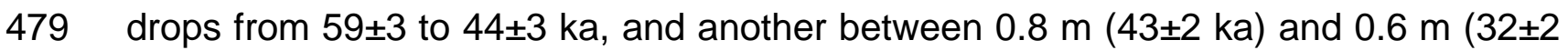
$480 \mathrm{ka}$ ). However, the spatial resolution of the data is insufficient to be confident of these 481 breaks and we confine ourselves to calculating the average sedimentation rate for the 
482 top $1 \mathrm{~m}$ of $0.031 \pm 0.005 \mathrm{~m} \mathrm{ka}^{-1}$. The OSL ages confirm that the Holocene soil is 483 missing but the weak soil developed during the warming period of the Last Glacial, i.e. 484 MIS 3, so we cannot tell whether recent deposition rates are comparable with the 485 previous interglacial.

486

487 It appears that sedimentation rate was low during MIS 5 and accelerated at the 488 onset of MIS 4. At MIS 4 there was a period of very high dust deposition followed by 489 slow deposition throughout MIS 3.

490

491 Conclusions

492

493 We have examined both quartz and feldspar from the NYZG loess deposit in 494 northeastern China in detail. The quartz is sensitive, fast component dominated and 495 not surprisingly has excellent luminescence characteristics 496

497 Based on studies of dose recovery and equivalent dose as a function of test dose 498 size measured using the pIRIR 290 signal, we deduce that the test dose employed 499 should be related to the equivalent dose under investigation. Typically it would appear 500 that a test dose of 15 to $80 \%$ of the $D_{e}$ is most likely to give a satisfactory dose 501 estimate. Furthermore, we question the interpretation of MET-pIRIR data in terms of 502 increasing stability with increasing stimulation temperature. Even in a sample of 
503 non-finite feldspar age, the signal resulting from a low first-IR stimulation temperature

504 in a pIRIR 290 protocol only results in a sensitivity corrected luminescence signal $\sim 5 \%$

505 lower than that resulting from a high first-IR stimulation temperature; contrast this with

506 the $\sim 21 \%$ underestimate at low MET-temperatures. It appears that this underestimate

507 is at least in part an artefact of variation in dose recovery with stimulation temperature.

508 Nevertheless, both methods suggest the presence of some instability ( $10 \%$ signal

509 loss) at field saturation even at the highest (first IR) stimulation temperature (Fig. 7).

510

511 Finally, we have investigated the relative bleaching characteristics of quartz OSL

512 and the IR50 and pIRIR290 feldspar signals and confirmed that quartz OSL bleaches

513 considerably more rapidly than feldspar, reaching $<10 \%$ of its initial value when IR $_{50}$

514 has only lost $<50 \%$ and pIRIR $290<20 \%$. These data support the suggestion that the

515 ratios of the three signals can be used as indicators of the degree of bleaching of the

516 more sensitive signals. Our pIRIR 290 data are also consistent with an unbleachable

517 residual signal (equivalent to $6.2 \pm 0.7 \mathrm{~Gy}$ ) underlying an exponentially bleached 518 signal.

519

520 At this site, quartz OSL and pIRIR290 ages are in agreement back to $\sim 70 \mathrm{ka}$. For

521 older sediments we deduce that quartz increasingly underestimates the deposition

522 age. Based on our preferred ages we conclude that sedimentation rates increased

523 rapidly during the Last Glacial, peaking at MIS $4(\sim 60 \mathrm{ka})$ at $0.16_{-0.05}^{+0.12} \mathrm{~m} \mathrm{ka}^{-1}$. During 
524 MIS 3 this sedimentation rate was considerably lower but remained high at $5250.031 \pm 0.005 \mathrm{~m} \mathrm{ka}^{-1}$ Unfortunately, MIS 2 and 1 are missing at this site.

526

527 This study has demonstrated the consistency of quartz and feldspar ages (and 528 probably their reliability) over the last glacial period. Beyond that, quartz is 529 increasingly unreliable and it appears that feldspar ages are consistently more 530 accurate.

531

532 Acknowledgements - We are indebted to Xu Zhiwei, Qiu Zhimin and Zhuo haixin for 533 assistance during field work and to Yang Chuanbin for support in the laboratory. We 534 thank Prof. Jakob Wallinga, an anonymous reviewer and Prof. Jan Piotrowski for their 535 useful comments on the original manuscript. This research is supported by the 536 National Natural Science Foundation of China (41371203, 41472138). Jan-Pieter 537 Buylaert received financial support from The Danish Independent Research Council 538 (Steno grant no. 11-104566).

539

540 References

541

542 Aitken, M.J., 1985. Thermoluminescence Dating. Academic Press, London.

543 Alexanderson, H. \& Murray, A. S. 2012: Luminescence signals from modern sediments in a glaciated

544 bay, NW Svalbard. Quaternary Geochronology 10, 250-256.

545 Ballarini, M., Wallinga, J., Wintle, A. G. \& Bos, A. J. J. 2007: A modified SAR protocol for optical dating 546 of individual grains from young quartz samples. Radiation Measurements 42, 360-369.

547 Bøtter-Jensen, L., Andersen, C.E., Duller, G.A.T. \& Murray, A.S. 2003: Developments in radiation, 
548 stimulation and observation facilities in luminescence measurements. Radiation Measurements 37,

$549 \quad 535-541$.

550 Buylaert, J. P., Murray, A. S., Thomsen, K. J. \& Jain, M. 2009: Testing the potential of an elevated

551 temperature IRSL signal from K-feldspar. Radiation Measurements 44, 560-565.

552 Buylaert, J.P., Jain, M., Murray, A.S., Thomsen, K.J., Thiel, C. \& Sohbati, R. 2012: A robust feldspar

553 luminescence dating method for Middle and Late Pleistocene sediments. Boreas 41, 435-451.

554 Buylaert, J.P., Murray, A.S., Vandenberghe, D., Vriend, M., De Corte, F. \& Van den haute, P. 2008:

555 Optical dating of Chinese loess using sand-sized quartz: establishing a time frame for Late Pleistocene

556 climate changes in the western part of the Chinese Loess Plateau. Quaternary Geochronology 3,

$55799-113$

558 Buylaert, J.P., Thiel, C., Murray, A.S., Vandenberghe, D., Yi, S. \& Lu, H. 2011: IRSL and post IR-IRSL

559 residual doses recorded in modern dust samples from the Chinese loess plateau. Geochronometria 38,

$560 \quad 432-440$.

561 Buylaert, J.P., Vandenberghe, D., Murray, A.S., Huot, S., De Corte, F. \& Van den haute, P. 2007:

562 Luminescence dating of old (>70 ka) Chinese loess: a comparison of single-aliquot OSL and IRSL

563 techniques. Quaternary Geochronology 5, 9-14.

564 Buylaert, J.P., Murray, A.S., Gebhardt, A.C., Sohbati, R., Ohlendorf, C., Thiel, C., Wastegård, S., 565 Zolitschka, B. \& The PASADO Science Team. 2013: Luminescence dating of the PASADO core 566 5022-1D from Laguna Potrok Aike (Argentina) using IRSL signals from feldspar. Quaternary Science 567 Reviews 71,70-80.

568 Cande, S.C. \& Kent, D.V. 1995: Revised calibration of the geomagnetic polarity timescale for the Late 
Cretaceous and Cenozoic. Journal of Geophysical Research 100, 6093-6095.

570 Chapot, M.S., Roberts, H.M., Duller, G.A.T. \& Lai, Z.P. 2012: A comparison of natural-and

571 laboratory-generated dose response curves for quartz optically stimulated luminescence signals from

572 Chinese Loess. Radiation Measurements 47, 1045-1052.

573 Cunningham, A.C. \& Wallinga, J. 2010: Selection of integration time intervals for quartz OSL decay

574 curves. Quaternary Geochronology 5, 657-666.

575 Fu, X. \& Li, S.H. 2013: A modified multi-elevated-temperature post-IR IRSL protocol for dating

576 Holocene sediments using K-feldspar. Quaternary Geochronology 17, 44-54.

577 Gao, F. \& Wang, B.S. 2008: A study on global warming and the temperature changes in the northeast

578 region. Marine Forecasts 25, 25-30 (in Chinese).

579 Guérin, G., Mercier, N. \& Adamiec, C. 2011: Dose-rate conversion factors: update. Ancient TL 29, 5-8.

580 Guralnik, B., Li, B., Jain, M., Chen, R., Paris, R.B., Murray, A., Li, S.-H., Pagonis, V., Valla, P. G. \&

581 Herman, F. 2015: Radiation-induced growth and isothermal decay of infrared-stimulated luminescence

582 from feldspar. Radiation Measurements 81, 224-231.

583 Huntley, D. J. \& Baril, M. R.1997: The K content of the K-feldspars being measured in optical dating or

584 in thermoluminescence dating. Ancient TL 15, 11-13.

585 Huntley, D. J. \& Lian, O. B. 2006: Some observations on tunnelling of trapped electrons in feldspars

586 and their implications for optical dating. Quaternary Science Reviews 25, 2503-2512.

587 Huntley, D.J. \& Lamothe, M. 2001: Ubiquity of anomalous fading in K-feldspars and the measurement

588 and correction for it in optical dating. Canadian Journal of Earth Sciences 38, 1093-1106.

589 Hütt, G., Jaek, I. \& Tchonka, J. 1988: Optical dating: K-feldspars optical response stimulation spectra. 
591 Jain, M. \& Ankjærgaard, C. 2011: Towards a non-fading signal in feldspar: insight into charge transport

592 and tunnelling from time resolved optically stimulated luminescence. Radiation Measurements 46, $593 \quad 292-309$.

594 Jain, M., Murray, A.S. \& Bøtter-Jensen, L. 2003: Characterisation of blue-light stimulated luminescence 595 components in different quartz samples: implications for dose measurement. Radiation Measurements $59637,441-449$.

597 Kars, R. H., Busschers, F. S. \& Wallinga, J. 2012: Validating post IR-IRSL dating on K-feldspars 598 through comparison with quartz OSL ages. Quaternary Geochronology 12, 74-86.

599 Kars, R.H., Reimann, T., Ankjærgaard, C. \& Wallinga, J. 2014a: Bleaching of the post-IR IRSL signal: 600 new insights for feldspar luminescence dating. Boreas 37, 441-449.

601 Kars, R.H., Reimann, T. \& Wallinga, J., 2014b: Are feldspar SAR protocols appropriate for post-IR IRSL 602 dating? Quaternary Geochronology 22, 126-136.

603 Lai, Z.P. 2010: Chronology and the upper dating limit for loess samples from Luochuan section in the 604 Chinese Loess Plateau using quartz OSL SAR protocol. Journal of Asian Earth Sciences 37, 176-185. 605 Lai, Z.P. \& Fan, A.C. 2014: Examining quartz OSL age underestimation for loess samples from 606 Luochuan in the Chinese Loess Plateau. Geochronometria 41, 57-64.

607 Li, B., Li, S. H., Wintle, A. G. \& Zhao, H. 2008: Isochron dating of sediments using luminescence of 608 K-feldspar grains. Journal of Geophysical Research 113, F02026.

609 Li, B. \& Li, S.H. 2011: Luminescence dating of K-feldspar from sediments: a protocol without 610 anomalous fading correction. Quaternary Geochronology 6, 468-479. 
611 Li, B. \& Li, S.H. 2012a: Luminescence dating of Chinese loess beyond 130 ka using the non-fading

612 signal from K-feldspar. Quaternary Geochronology 10, 24-31.

613 Li, B. \& Li, S.H. 2012b: A reply to the comments by Thomsen et al. on "Luminescence dating of

614 K-feldspar from sediments: A protocol without anomalous fading correction". Quaternary

615 Geochronology 8, 49-51.

616 Liu, T.S. \& Ding Z.L. 1998: Chinese loess and the paleomonsoon. Annual Reviews of Earth and

617 Planetary Sciences 26, 111-145.

618 Liu, T., 1985. Loess and the Environment, 65 pp (in Chinese).

619 Lowick, S.E., Trauerstein, M. \& Preusser, F. 2012: Testing the application of post IR-IRSL dating to fine

620 grain waterlain sediments. Quaternary Geochronology 8, 33-40.

621 Mejdahl, V. \& Bøtter-Jensen, L. 1994: Luminescence dating of archaeological materials using a new

622 technique based on single aliquot measurements. Quaternary Science Reviews 13, 551-554.

623 Murray, A.S. 1996: Developments in optically stimulated luminescence and photo-transferred

624 thermoluminescence dating of young sediments: Application to a 2000-year sequence of flood 625 deposits. Geochimica et Cosmochimica Acta 60, 565-576.

626 Murray, A. S. \& Wintle, A. G. 2000: Luminescence dating of quartz using an improved single-aliquot

627 regenerative-dose protocol, Radiation Measurements 32, 57-73.

628 Murray, A. S., Buylaert, J. P., Thomsen, K. J. \& Jain, M. 2009: The effect of preheating on the IRSL 629 signal from feldspar. Radiation Measurements 44, 554-559.

630 Murray, A.S., Thomsen, K.J., Masuda, N., Buylaert, J.P. \& Jain, M. 2012: Identifying well-bleached 631 quartz using the different bleaching rates of quartz and feldspar luminescence signals. Radiation 
633 Murray, A. S., Schmidt, E.D., Stevens,T., Buylaert, J.P., Marković,S.B., Tsukamoto, S. \& Frechen, M.

634 2014: Dating Middle Pleistocene loess from Stari Slankamen (Vojvodina, Serbia) — Limitations

635 imposed by the saturation behaviour of an elevated temperature IRSL signal. Catena 117, 34-42.

636 Murray, A.S. \& Wintle, A.G. 2003: The single aliquot regenerative dose protocol: potential for 637 improvements in reliability. Radiation Measurements 37, 377-381.

638 Nian, X.M., Bailey, R.M. \& Zhou, L.P. 2012: Investigations of the post-IR IRSL protocol applied to single

639 K-feldspar grains from fluvial sediment samples. Radiation Measurements 47, 703-709.

640 Prescott, J.R. \& Hutton, J.T. 1994: Cosmic ray contributions to dose rates for luminescence and ESR

641 dating: large depths and long-term time variations. Radiation Measurements 23, 497-500.

642 Qin, J.T. \& Zhou, L.P. 2012: Effects of thermally transferred signals in the post-IR IRSL SAR protocol.

643 Radiation Measurements 47, 710-715.

644 Reimann, T. \& Tsukamoto, S. 2012: Dating the recent past (<500 years) by post-IR IRSL feldspar e

645 examples from the North Sea and Baltic Sea coast. Quaternary Geochronology 10, 180-187.

646 Reimann, T., Tsukamoto, S., Naumann, M. \& Frechen, M. 2011: The potential of using K-rich feldspars

647 for optical dating of young coastal sediments e a test case from Darss-Zingst peninsula (southern

648 Baltic Sea coast). Quaternary Geochronology 6, 207-222.

649 Roberts, H.M. 2008: The development and application of luminescence dating to loess deposits: a

650 perspective on the past, present and future. Boreas 37, 483-507.

651 Roberts, H.M. 2012: Testing Post-IR IRSL protocols for minimising fading in feldspars, using Alaskan 652 loess with independent chronological control. Radiation Measurements 47, 716-724. 
653 Singarayer J.S. \& Bailey R. M. 2003: Further investigations of the quartz optically stimulated

654 luminescence components using linear modulation. Radiation Measurements 37,451-458.

655 Sohbati, R., Murray, A. S., Buylaert, J.P., Ortuño, M., Cunha, P.P. \& Masana, E. 2012: Luminescence 656 dating of Pleistocene alluvial sediments affected by the Alhama de Murcia fault (eastern Betics, Spain)

657 - a comparison between OSL, IRSL and post-IR IRSL ages. Boreas 41, 250-262.

658 Spooner, N.A. 1994: The anomalous fading of infrared stimulated luminescence from feldspar.

659 Radiation Measurements 23, 625-632.

660 Stevens, T., Armitage, S. J., Lu, H. \&Thomas, D.S.G. 2006: Sedimentation and diagenesis of Chinese

661 loess: Implications for the preservation of continuous, high-resolution climate records. Geology 34 ,

$662849-852$.

663 Stevens, T., Markovic', S. B., Zech, M. \& Sümegi, P. 2011: Dust deposition and climate in the

664 Carpathian Basin over an independently dated last glacial-interglacial cycle. Quaternary Science

665 Reviews 30, 662-681.

666 Sun, F.H., Yang S.Y. \& Ren G.Y., 2007: Decade Variations of precipitation event frequency, intensity 667 and duration in the Northeast China. Journal of Applied Meteorological Science 18, 610-618 (in 668 Chinese).

669 Thiel, C., Buylaert, J.-P., Murray, A. S., Terhorst, B., Hofer, I.,Tsukamoto, S. \& Frechen, M. 2011a: 670 Luminescence dating of the Stratzing loess profile (Austria) - Testing the potential of an elevated 671 temperature post-IR IRSL protocol. Quaternary International 234, 23-31.

672 Thiel, C., Buylaert J.-P., Murray, A.S. \& Tsukamoto, S. 2011b: On the applicability of post-IR IRSL 673 dating to Japanese loess. Geochronometria 38, 369-378. 
674 Thiel, C., Horváth, E. \& Frechen, M. 2014: Revisiting the loess/palaeosol sequence in Paks, Hungary:

675 A post-IR IRSL based chronology for the 'Young Loess Series'. Quaternary International 319, 88-98.

676 Thiel, C., Buylaert, J.-P., Murray, A.S., Elmejdoub, N. \& Jedoui, Y. 2012: A comparison of TT-OSL and

677 post-IR IRSL dating of coastal deposits on Cap Bon peninsula, north-eastern Tunisia. Quaternary 678 International 10, 209-217.

679 Thomsen, K.J., Murray, A.S. \& Jain, M. 2011: Stability of IRSL signals from sedimentary K-feldspar 680 samples. Geochronometria 38, 1-13.

681 Thomsen, K.J., Murray, A.S., Jain, M. \& Bøtter-Jensen, L. 2008: Laboratory fading rates of various

682 luminescence signals from feldspar-rich sediment extracts. Radiation Measurements 43, 1474-1486.

683 Thomsen, K.J., Murray, A.S., Buylaert, J.-P., Jain, M., Hansen, J.H. \& Aubry, T. 2016: Testing 684 single-grain quartz OSL methods using sediment samples with independent age control from the 685 Bordes-Fitte rockshelter (Roches d'Abilly site, Central France). Quaternary Geochronology 31, 77-79..

686 Timar-Gabor, A. \& Wintle, A.G. 2013: On natural and laboratory generated dose response curves for 687 quartz of different grain sizes from Romanian loess. Quaternary Geochronology 18, 34-40.

688 Tsukamoto,S., Kataoka, K., Oguchi,T., Murray, A.S. \& Komatsu,G. 2014: Luminescence dating of 689 scoria fall and lahar deposits from SommaeVesuvius, Italy. Quaternary Geochronology 20, 39-50.

690 Vandenberghe, D., De Corte, F., Buylaert, J.P., Kučera, J. \& Van den haute, P. 2008: On the internal 691 radioactivity in quartz. Radiation Measurements 43, 771-775.

692 Wallinga, J., Murray, A.S. \& Wintle, A.G. 2000: The single-aliquot regenerative-dose (SAR) protocol 693 applied to coarse-grain feldspar. Radiation Measurements 32, 529-533.

694 Wallinga, J., Murray, A.S., Duller, G.A.T. \& Törnqvist, T. E. 2001: Testing optically stimulated 
695 luminescence dating of sand-sized quartz and feldspar from fluvial deposits. Earth and Planetary

696 Science Letters 193, 617-630.

697 Wintle, A.G. \& Murray, A.S. 2006: A review of quartz optically stimulated luminescence characteristics

698 and their relevance in single aliquot regeneration dating protocols. Radiation Measurements 41 , $699 \quad 369-391$.

700 Zander, A. \& Hilgers, A. 2013: Potential and limits of OSL, TT-OSL, IRSL and pIRIR290 dating methods 701 applied on a Middle Pleistocene sediment record of Lake El'gygytgyn, Russia. Climate of the Past 9, $702 \quad 719-733$.

703 Zeng, L., Lu, H.Y., Yi, S.W., Xu, Z.W., Qiu, Z.M., Yang, Z.Y. \& Li, Y.X. 2011: Magnetostratigraphy of 704 loess in northeastern China and paleoclimatic changes. Chinese Science Bulletin (Chinese Ver) 56, $705 \quad 2267-2275$.

706 Zhao, H. \& Li, S.H. 2005: Internal dose rate to K-feldspar grains from radioactive elements other than 707 potassium. Radiation Measurements 40, 84-93.

708 Zhou, L.P. \& Shackleton, N.J. 2001: Photon-stimulated luminescence of quartz from loess and effects 709 of sensitivity change on palaeodose determination. Quaternary Science Reviews 20, 853-857.

710

\section{Figure captions}

712

713 Fig.1. Map of loess distribution in northeastern China showing location of the study 714 site (Niuyangzigou, NYZG) and its stratigraphy. L and S represent loess and 715 palaeosol units, respectively. From the top to the bottom, the loess-soil sequences 
716 are named as $L_{1}$ and $S_{1}$ followed the designation of Liu (1985). Based on the OSL

717 data the Holocene soil (So) appears to be missing.

718

719 Fig.2. Luminescence characteristics for coarse-grained (63-90 $\mu \mathrm{m})$ quartz. A. and B.

720 Dose-response curves for aliquots of samples 138101 and 138115 respectively (inset

721 shows the natural decay curves measured at $125^{\circ} \mathrm{C}$ and at $90 \%$ blue LED power). C.

722 Preheat plateau tests of samples 138101 and 138115. Three aliquots were measured

723 at each temperature and error bars represent 1 standard error. The dash-dot line is

724 drawn at the average $\mathrm{D}_{\mathrm{e}}$ over the $180-280{ }^{\circ} \mathrm{C}$ interval. $\mathrm{D}$. Dose recovery ratio as a

725 function of preheat temperature for samples 138101 and 138107 . Aliquots were first

726 bleached with blue light at room temperature ( $2 \times 100 \mathrm{~s}$ separated by a $10 \mathrm{ks}$ pause)

727 and then given a dose of 78.5 Gy and 156 Gy for 138101 and 138107, respectively.

728 The solid line is drawn at unity and the dashed lines at $\pm 10 \%$. Three aliquots were

729 measured per preheat temperature and error bars represent one standard error. The

730 inset shows a histogram of recycling ratios for all samples (measured as part of De

731 determination).

732

733 Fig.3. A. Natural signals and dose-response curves for coarse-grained quartz and

734 K-feldspar of sample 138115. Data were fitted with a sum of two saturating 735 exponential functions of the form $y=a \times(1-\exp (-b x))+c \times(1-\exp (-d x))$. The 736 sensitivity-corrected luminescence ( $L_{x} / T_{x}$ values) was normalized to the fitted 
737 saturation values ('a+c'). B. $L_{x} / T_{x}$ plots for the pIRIR 290 signal for a set of samples 738 down the section. Three aliquots were measured for each sample but only one

739 representative aliquot is shown. Sample $138101\left(L_{x}=100 \mathrm{~Gy} ; T_{x}=30 \mathrm{~Gy}\right) ; 138102\left(L_{x}\right.$ $\left.740=999 \mathrm{~Gy} ; \mathrm{T}_{\mathrm{x}}=300 \mathrm{~Gy}\right) ; 138108\left(\mathrm{Lx}_{\mathrm{x}}=216 \mathrm{~Gy} ; \mathrm{T}_{\mathrm{x}}=65 \mathrm{~Gy}\right) ; 138115\left(\mathrm{~L}_{\mathrm{x}}=362 \mathrm{~Gy} ; \mathrm{T}_{\mathrm{x}}=\right.$ $741108 \mathrm{~Gy})$ and the B/M boundary sample 1535 ( $\left.\mathrm{L}_{\mathrm{x}}=999 \mathrm{~Gy} ; \mathrm{T}_{\mathrm{x}}=300 \mathrm{~Gy}\right)$.

743 Fig.4. Result of the dose recovery test for pIRIR 290 . A. Plot of the dose recovery ratio 744 versus test dose size. The test dose size various from 5 to $260 \%$ of the total 745 (natural+added) dose. The dose recovery ratio was calculated as the measured dose

746 divided by the sum of the natural and the given dose. The solid line is drawn at unity 747 and the dashed-dot lines at $\pm 5 \%$. B. dose recovery results show as the measured 748 dose versus added dose.

749

750 Fig.5. Dependence of $D_{e}$ on test dose size for the uppermost (138101), middle 751 (138108) and lowermost (138115) samples from the upper $3.2 \mathrm{~m}$ section. The 752 dash-dot line is the average of the $\mathrm{D}_{\mathrm{e}}$ value for test doses ranging between 15 and $80 \%$ 753 of the total (natural + added) dose.

754

755 Fig.6. Comparison of pIRIR 290 and MET-pIRIR. A. and B. Dependence of $D_{e}$ on prior 756 IR stimulation temperature for the uppermost (138101) and lowermost (138115) 757 samples from the upper $3.2 \mathrm{~m}$ section. Three aliquots were measured at each 
758 temperature and error bars represent one standard error. The dash-dot line is drawn

759 at the average $D_{e}$ over the $50-260{ }^{\circ} \mathrm{C}$ interval for the pIRIR 290 . C. Dependence of 760 dose recovery ratio on prior IR stimulation temperature for the uppermost sample 761 (138101). Three aliquots were measured at each temperature and error bars 762 represent one standard error. The dash-dot line is drawn at unity on the vertical axis.

764 Fig.7. Fraction of saturation for both the pIRIR 290 and MET-pIRIR signals for a sample 765 from below to the B/M boundary (burial dose $>2000 \mathrm{~Gy}$ ). A. Fraction of saturation 766 measured using the large test dose. B. Fraction of saturation measured using the 767 small test dose. All the data were fitted with a single saturating exponential function.

768 Each data point is an average of three aliquots and error bars represent one standard 769 error. The solid line is drawn at unity and the dashed line at 0.9.

770

771 Fig.8. Comparison of age and bleaching rate for the quartz OSL, feldspar IR $\mathrm{R}_{50}$ and 772 pIRIR290 signals. A. Quartz OSL and feldspar $\mathrm{IR}_{50}$ ages plotted as a function of 773 pIRIR 290 age. The $\operatorname{IR}_{50}$ and pIRIR 290 ages have a residual dose of $0.6 \pm 0.1$ Gy and $7746.2 \pm 0.7$ Gy subtracted from the $D_{e}$ and are not corrected for fading. The vertical 775 dashed line shows the upper quartz OSL dating limit. B. Residual quartz OSL, 776 feldspar $I_{50}$ and pIRIR 290 doses for different Hönle SOL2 solar simulator bleaching 777 times for sample 138115 . The solid line was derived from fitting the IR50 to pIRIR290 $\mathrm{De}_{\mathrm{e}}$ 778 values for all 15 samples. Each data point is an average of three aliquots and error 
bars represent one standard error.

780

781 Fig.9. The relationship between the residual dose and $D_{e}$ obtained with the pIRIR 290 782 protocol on three samples $(138102,-08,-15)$. A. and C. Average residual dose 783 obtained after different Hönle SOL2 solar simulator bleaching times as a function of 784 the pIRIR 290 and $I R_{50} D_{e}$, respectively. Each point is the average residual dose of 785 three to twelve aliquots per sample obtained after the given exposure times and error 786 bars represent 1 standard error. The relationship between residual dose and 787 equivalent dose is described by a linear fit for each exposure time. Inset in $A$. is the 788 same relationship for all 15 samples for a single bleaching time of $15 \mathrm{~h}$. B. and D. 789 Intercept of the linear fits with the $y$-axis from A. and C. as a function of exposure 790 time.

791

792 Fig.10. Stratigraphy, quartz OSL and feldspar pIRIR 290 ages for NYZG. The ages are 793 plotted against the section depth. Open circles represent the quartz OSL ages and 794 closed circles represent the pIRIR 290 ages. Sedimentation rates were derived from 795 linear regression.

796

797 Table captions

798

799 Table 1. Summary of sample code and depth, radionuclide concentrations, calculated 
800 dose rates, OSL and pIRIR $290 D_{e}$ values and luminescence ages. The absolute 801 uncertainty on the water content is $\pm 5 \%$. The pIRIR $R_{290} D_{e}$ values have a residual dose 802 of $6.2 \pm 0.7$ Gy subtracted from the measured value while the pIRIR 290 ages are not 803 corrected for fading. (n) denotes the number of aliquots contributing to the De.

804

805 Table 2. Outline of dose measurement protocols used in this study. SAR protocol 806 after Murray \& Wintle (2000, 2003), post-IR IRSL protocol after Thiel et al. (2011a), 807 MET-post-IR IRSL after Li \& Li (2012a). For the 'natural' sample, the give dose $=0$. T 808 varies from 50 to $260{ }^{\circ} \mathrm{C}$. The whole sequence is repeated for several regenerative 809 doses including a zero dose and a repeat dose. 